\title{
Extraction and Characterization of Chitosan from Indian Prawn (Fenneropenaeus Indicus) and its Applications on Waste Water Treatment of Local Ghee Industry
}

\author{
Zeenat M. Ali ${ }^{1}$, Abdul Jabbar Laghari ${ }^{2}$, Abdul Khalique Ansari ${ }^{1}$, \\ Mohammad Yar Khuhawar ${ }^{2}$ \\ ${ }^{1}$ Mehran University of Engineering \& Technology, Jamshoro, Sindh, Pakistan \\ ${ }^{2}$ Institute of Advanced Research Studies in Chemical Sciences, University of Sindh, Jamshoro, Pakistan
}

\begin{abstract}
Chitosan; an organic biopolymer, a natural biodegradable material with high molecular weight was derived and extracted locally from Indian prawn (Fenneropenaeus Indicus) through deacetylation process. Chitosan carries charges at different $p H$ levels, below $p H 6.5$ it carries strong cationic charges and above this $p H$ strong anionic charges, therefore it has strong affinity for ions because it comprises of sequenced amino groups $\left(-\mathrm{NH}_{2}\right)$ and hydroxyl groups $(-\mathrm{OH})$. In present study, extracted chitosan was characterized by FTIR, SEM and EDS, the same was successfully applied for the treatment of industrial waste water of ghee industry located in SITE area of Hyderabad (Sindh), Pakistan. The experimental conditions such as; chitosan dosage, optimum pH and mixing times were examined for flocculation process. The chitosan showed marked difference by successfully flocculated the negatively charged suspended particles, thereby reducing Chemical Oxygen Demand (COD), Turbidity, Total Dissolved Solids (TDS) and Conductivity levels in industrial waste water. The secondary parameter equally important determined was Dissolved Oxygen (DO) which is required to sustain aquatic life. The experimental optimum conditions were obtained at 1\% chitosan in $1 M$ acetic acid, pH 4 and 5 minutes of mixing time at $1000 \mathrm{rpm}$ and 25 minutes of settling time. The highest flocculation efficiency of chitosan observed under these conditions was $80.1 \%$ COD removal, $91.8 \%$ Turbidity removal, $72.5 \%$ TDS removal and $73.7 \%$ reduction in conductivity. It is found to absorb grease, toxic material, fats and oils. The main advantages of chitosan are; biodegradability, nontoxic in nature having fast settling velocity, low dosage, high removal efficiency, being economical, and cost efficient.
\end{abstract}

Keywords - Biopolymer, Chitosan, Flocculant, Indian Prawn, Waste Water

\section{INTRODUCTION}

Chitosan in the light of various authors shows versatility in properties whether Physico-Chemical or Biological. They discussed various applications in fields of interest to human beings, i.e. Cosmetics, besides pharmaceuticals, fields of ophthalmology, to biotechnology, agriculture, textiles and nutrition [8], [15], [23], [27], [31], [37]. This biopolymer used as flocculant has fetched attention of researchers in the last decade for treatment of water and waste water in order to remove or reduce dissolved and particulate matter. It is worth to focus on development of chitosan-based biopolymers as useful coagulants and flocculants for water and waste water treatments [6], [16], [28], [29], [38], [41]. Their coagulation and flocculation properties can be used to remove particulate inorganic or organic suspensions, and also dissolved organic substances. Waste water from industries continuously discharged into ravines and rivers of fresh water without or with little treatment. In the year 2000, 1.1 billion persons remained without any access to improved drinking water [19]. According to WHO (World Health Organization) statistics the contaminated water contributed directly to the annual 2.2 million diarrhea-related deaths [36], and the number of persons drinking water contaminated by human sewage was much higher [34]. Therefore in the context of above discussion due to economic and political constraints, the universal provision of piped treated water is not currently feasible, leaving millions without access to safe drinking water [35]. Chitosan is $\mathrm{pH}$ dependent organic material in aqueous solutions therefore it has strong affinity for ions. It is finding potential applications in removing heavy particles and many pathogens from different solvents as well as agriculture and food industries [9], [21], [33]. After extraction of Chitosan from Indian prawns the organic material was examined for characterization and the results obtained using different techniques (FTIR, NMR Spectroscopy, X-ray scattering, sorption techniques) conducted commercially from the labs of PCSIR- Karachi (Sindh), Pakistan, suggest that Chitosan has the same behavior as that of cellulose, with characteristic features like, structure, hydrogen bonding, crystalline and polymorphic nature available in literature [13], [14], [22]. Attempts are being made to use chitosan for treatment and purification of water with elimination of the suspended solids from solvents for many decades [20], [26]. Chitosan acts to make bigger flocs which can be settled in the bottom easily. During water treatment process it reduces COD levels in water bodies as well [7]. It is fat absorber/fat inhibitor when it is spread over water surface. It absorbs the grease, various toxic materials, fats and oils and heavy metals; resulting scum is formed over surface of the flowing water, which can easily be discarded. It has a number of commercial and possible biomedical uses. The main 
advantage in water treatment is biodegradable [1], [11] nontoxic nature [17], [30]. Hence sludge needs easier treatment. It is used for removing impurities like COD, TSS, having fast settling velocity, low dosage, high removal efficiency, economical, and cost efficient [10], [12]. As large amounts of crustacean shells are directly dumped or sent to land fill, but if chitosan were extracted from the shells then this would have provided extra income to individuals as well as fish industry to overcome the economic crises and economic depression of fishermen [5], [24].

\section{PRESENT WORK}

Attempts have been made to discover and extract organic flocculant polymer chitosan from locally available natural resources Indian Prawns (Fenneropenaeus Indicus) as shown in Figure-1. With high tendency of separation, safe and inert in the nature, easily degradable. After characterization the same was applied for treatment of waste water samples collected from local ghee industry of Hyderabad (SITE area).

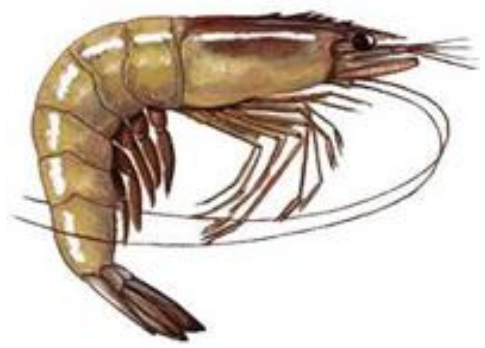

Fig.-1: Fenneropenaeus Indicus or Indian Prawn

\section{MATERIALS AND METHODS}

\subsection{Sample Collection}

A packet of $2 \mathrm{Kg}$ full of frozen Indian prawns was obtained from the officials of Marine Fisheries Department Pakistan, West Wharf Karachi (Sindh), Pakistan. Standard chitosan of MP Biomedical (Germany) for comparison purposes was purchased from scientific store Lahore, Pakistan.

\subsection{Extraction Process}

The meat portion of the sample was separated by small surgical forceps and the shells $(880 \mathrm{gm})$ were collected and dried directly to sunlight for three days at the temperature of $40^{\circ} \mathrm{C}-43^{\circ} \mathrm{C}$. Then weighed accurately to compute the moisture content and calculated as described in Eq.(1):

$$
\% \text { Moisture Content }=\frac{\text { Wet Sample }- \text { Dry Sample }}{\text { Wet Sample }} \times 100 \%
$$

This was found exactly $13.1 \%$. The remaining $(86.9 \%$ ) dry shells of Indian prawns were crushed by grinding and then passed through stationary sieve screen for obtaining the particles of mesh size of $100 \mu \mathrm{m}$. The Indian prawn sample of $100 \mu \mathrm{m}(78.3 \%)$ was taken into the Erlenmeyer flask and was added 3\% $\mathrm{NaOH}$ w/v. The solid and solvent ratio was maintained at 1:30, the mixture was heated to $90^{\circ} \mathrm{C}$ for more than 2 hours, cooled to room temperature and centrifuged with H-103N (Series Kokusan Ensinki Co. Ltd. Tokyo Japan), at $4000 \mathrm{rpm}$ for 20 minutes. The two fractions thus formed were separated, the upper alkali soluble supernatant portion and alkali insoluble lower precipitated part.

\subsection{Deacetylation and Demineralization Process}

The lower alkali insoluble precipitated part was collected in the flask and added $10 \%$ Acetic acid glacial (Merck) solution (twice in quantity) and was left for 24 hours with constant stirring on magnetic stirrer 78HW-1 (China). This step helped in demineralization of the sample. On next day the sample was adjusted to $\mathrm{pH} 9$ with the help of $4 \mathrm{M} \mathrm{NaOH}$ solution and put under reflux with condensers at $60^{\circ} \mathrm{C}$ for 6 hours with constant magnetic stirring. The sample was cooled at normal room temperature and centrifuged again. The supernatant was removed and the insoluble matter was first washed with double distilled water second time with absolute ethanol (Merck) and third time with acetone (Merck) using sintered glass funnel. Then the sample was dried in air, and then in laboratory desiccators for 48 hours. The sample appeared in lumps which were converted into uniform crystalline form with glass rod bashing. The chitosan material recovery was evaluated and found $61 \%$ of the original amount of $78.3 \%$ dried shells of $100 \mu \mathrm{m}$ mesh size.

\subsection{Chitosan Dose}


The $1 \%$ chitosan material (from Indian prawns) was prepared in $100 \mathrm{ml}$ of $1 \mathrm{M}$ acetic acid glacial (Merck) at $\mathrm{pH}$ 4 and left for 72 hours in $100 \mathrm{ml}$ quickfit flask with stop cock. $1 \%$ Standard chitosan of MP Biomedical (Germany) was prepared in same way for comparison. In a test tube $10 \mathrm{ml}$ Sample was added $1 \mathrm{ml}$ chitosan solution $(1 \% \mathrm{w} / \mathrm{v})$ as flocculant material added and subjected to stirring for 5 minutes then left for settling.

\subsection{Laboratory Instruments}

Following laboratory instruments were used.

- $\quad$ Turbidity Meter (HACH Model 2100 P, USA) with complete Accessories.

- Conductivity Meter (Thermo Orion Model 145, USA).

- The pH Meter (Thermo Orion Model 420 A+, USA) with combined glass electrode.

- COD Spectrometer: COD VARIO Lovibond SN-09/14076 (Germany) with Reactor ET-108 Lovibond.

- COD Method: Merck (Germany) COD Vials (Sample $2 \mathrm{~mL}$ and blank $2 \mathrm{~mL}$ )

$\begin{array}{lll}\circ & \text { Low } & (0-150 \mathrm{mg} / \mathrm{L}) \\ \circ & \text { Medium } & (0-1500 \mathrm{mg} / \mathrm{L}) \\ \circ & \text { High } & (0-15000 \mathrm{mg} / \mathrm{L})\end{array}$

- $\quad$ Dissolved Oxygen Meter, Model YSI Pro20, Cole-Parmer, (USA).

\section{RESULTS AND DISCUSSION}

The Indian prawn or white shrimp (Fenneropenaeus Indicus) of Arabian Sea belongs to the Phylum: Arthropoda, Class: Crustacea, Order: Decapoda and Family: Penaeidae. Indian prawn is full of Chitin; the second most abundant organic material after Cellulose, found in the exoskeleton of the Indian prawn. The Amino-biopolymer Chitosan is a natural biodegradable linear polysaccharide type material which was derived and extracted locally from chitin of Indian prawns by means of deacetylation and demineralization process whereby the organic material became soluble in dilute acidic medium. The chitosan molecule comprises of many amino groups $\left(-\mathrm{NH}_{2}\right)$ and hydroxyl groups $(-\mathrm{OH})$ on molecular chain thereby providing several properties to this organic compound as shown in Figure-2, that could be used for treatment and purification of waste water.

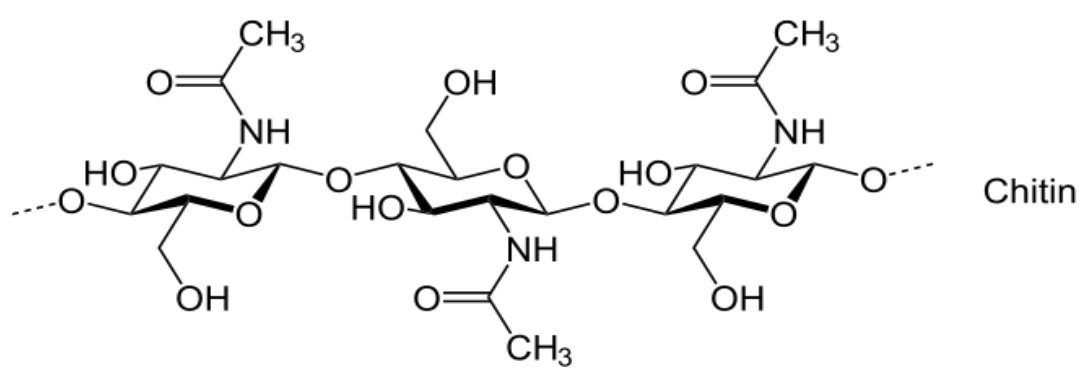

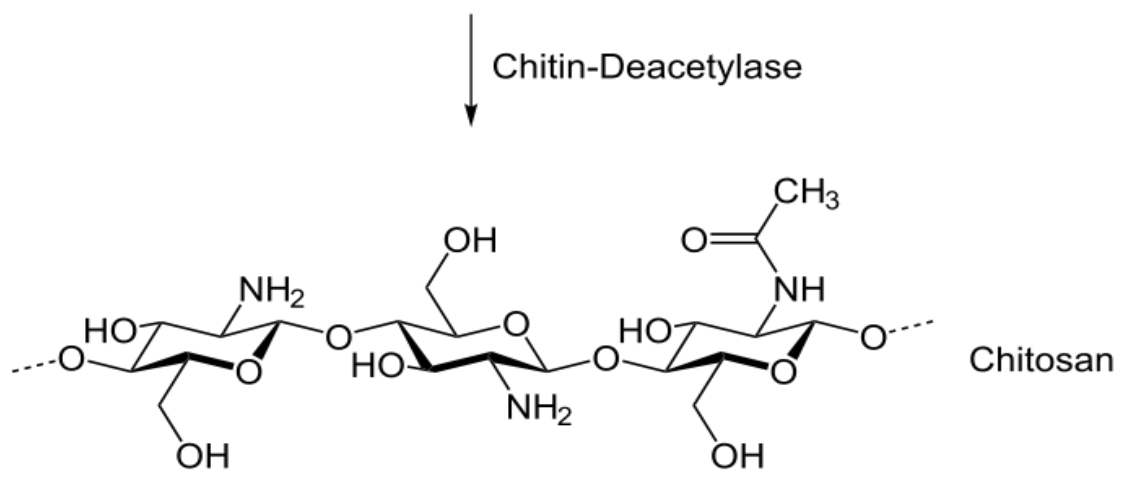

Fig.-2: Skeletal Structure of Chitin and Chitosan 
In present work, applications of chitosan are related with waste water treatment of local ghee industry. Waste water was treated via flocculation to remove microscopic dust particles, dirt, and other airborne substances that produced the cloudiness seen in waste water. These microscopic particles were small but they affected water's taste, appearance, and texture and could also cause illness. Chitosan as flocculant removed contaminants and loose, airborne particles from waste water. Flocculation process was performed in the laboratories of Chemical Engineering Department of MUET- Jamshoro, Pakistan. The process took several minutes for completion. The setup is shown in Figure-3.

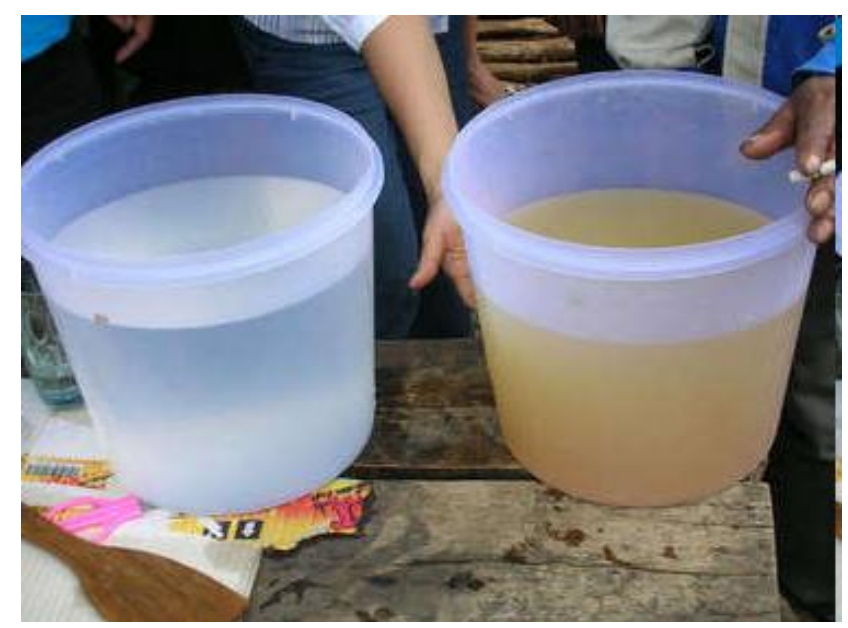

Fig.-3: Waste water treatment with Chitosan

The extracted chitosan was subjected to characterization by Nicolet AVATAR 330 FTIR with an attenuated total reflectance (ATR) accessory, smart performer (Thermo Nicolet, Thermo Electron Corporation USA) with $\mathrm{Zn}$-Se probe. The FTIR spectrum of chitosan as shown in Figure-4 confirms the presence of -O-H and $-\mathrm{N}-\mathrm{H}$ functional group stretching vibrations at $3430 \mathrm{~cm}^{-1},-\mathrm{C}-\mathrm{H}$ stretching vibrations at $2924 \mathrm{~cm}^{-1},-\mathrm{CH}_{2}-$ and $-\mathrm{CH}_{3}$ bending vibrations at 1259 and $1357 \mathrm{~cm}^{-1}$ respectively, whereas $-\mathrm{C}-\mathrm{N}$ stretching vibrations at 1320 $\mathrm{cm}^{-1}$ and $-\mathrm{C}-\mathrm{O}$ stretching vibrations at $1148 \mathrm{~cm}^{-1}$ were observed.

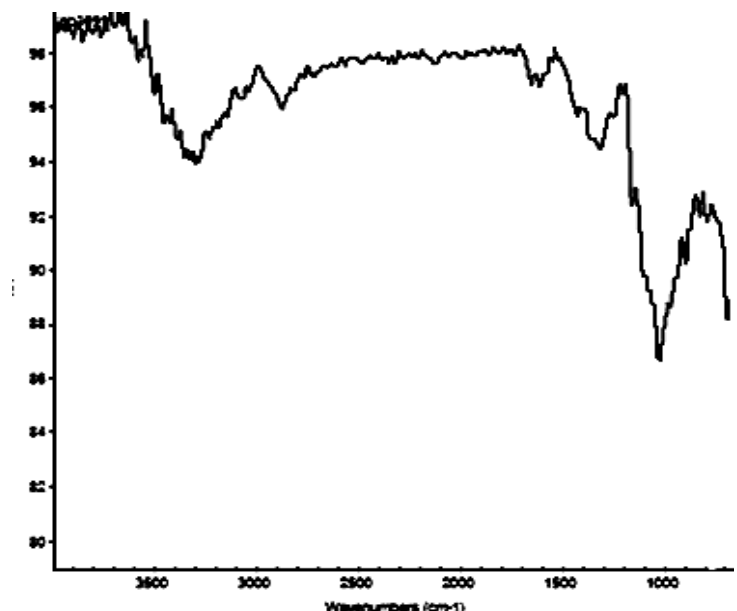

Fig.-4: FTIR Spectrum of Chitosan from Indian Prawn (Fenneropenaeus Indicus)

The newly extracted chitosan material was examined by scanning electron microscopy (SEM) technique (JEOL $6490 \mathrm{LV}$ - SEM by JAPAN). The facility was availed for characterization from Centre for Pure and Applied Geology, University of Sindh, Jamshoro, Pakistan. The SEM micrograph as shown in Figure5 was taken at $12 \mathrm{KV}$ power with X80 zoom power. Under these conditions the chitosan polymeric material with $200 \mu \mathrm{m}$ size showed the crystals elongated with nodes and angular shapes. The energy dispersive X-ray (EDS) technique was applied using BRUKER (133 eV) Japan, apparatus coupled with SEM instrument. The X-rays were penetrated through the electronic shells of the chitosan material and electrons were ejected from very first shell (K-shell). On the basis of that the percent elements were quantified as shown in Table-1. The Carbon content in chitosan was more than $51 \%$, Oxygen $41 \%$ and Nitrogen $5 \%$. 


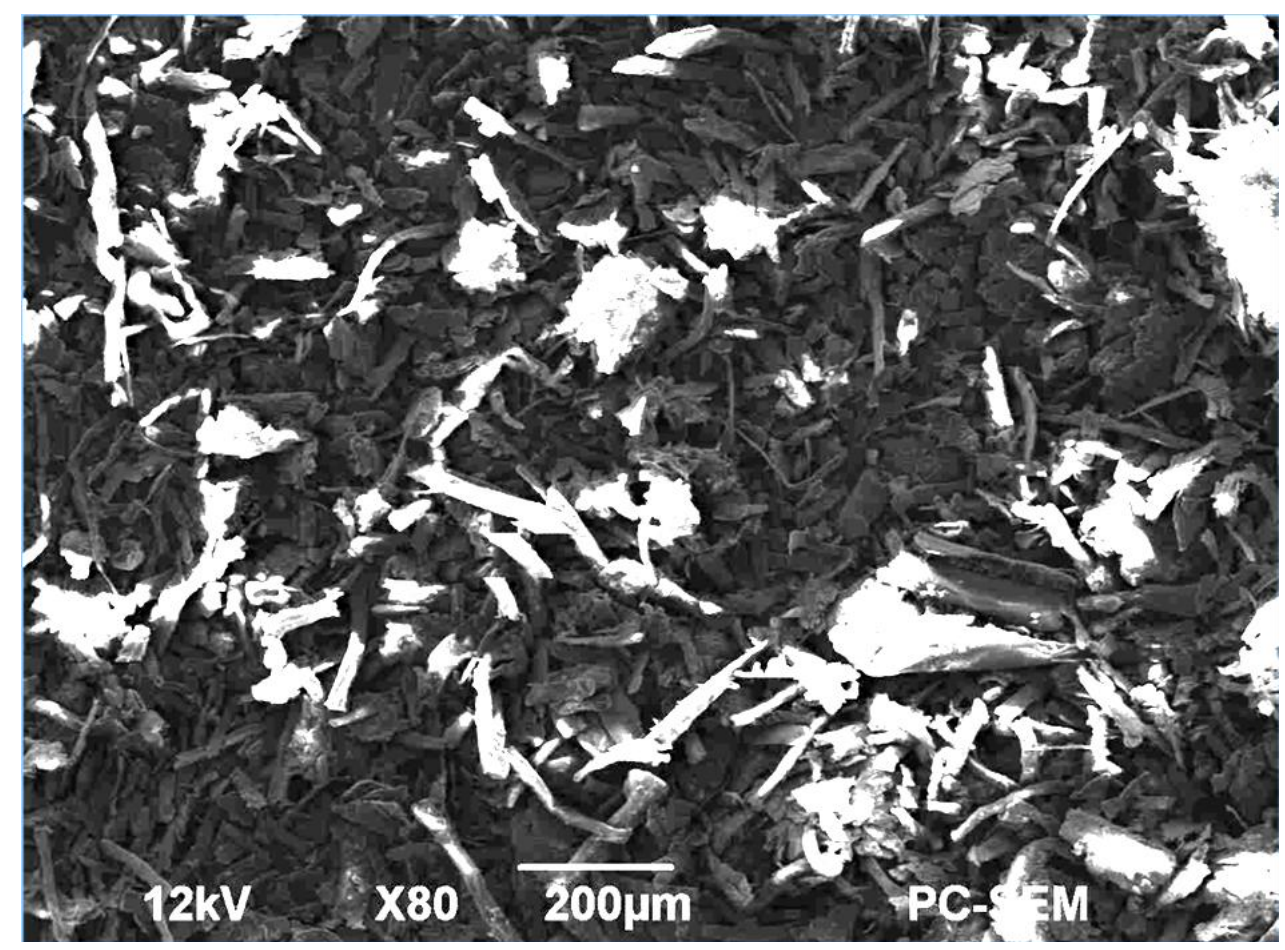

Fig.-5: SEM Micrograph of prepared Chitosan

Table-1. EDS Analysis of prepared Chitosan by BRUKER (133eV) Japan.

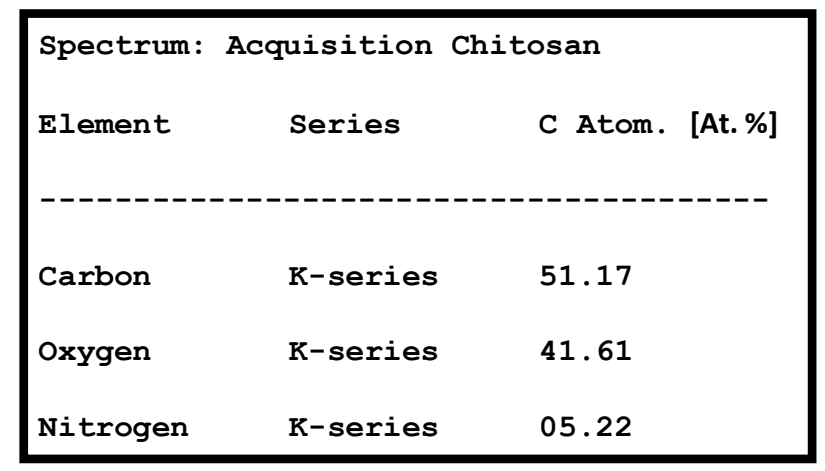

In present work, experimental studies were carried out on optimum dosage of Chitosan, maintenance of optimum experimental $\mathrm{pH}$ values, allowed mixing and settling times with respect to waste water samples of Ghee Industries of SITE area of Hyderabad (Sindh). Figure-6 shows the location of Ghee Industries of SITE area Hyderabad (Sindh). The investigated experiments were aimed to ascertain the capacity of Chitosan during flocculation systems. Since the waste water discharge from ghee industry always contains higher levels of Chemical Oxygen Demand (COD) therefore it is marked as the capacity indicator for Chitosan intake. The other supporting parameters are Conductivity, TDS and Turbidity with minor or secondary parameters; Biochemical Oxygen Demand (BOD) and Dissolved Oxygen (DO) during the experimental studies [25], [39], [40]. 


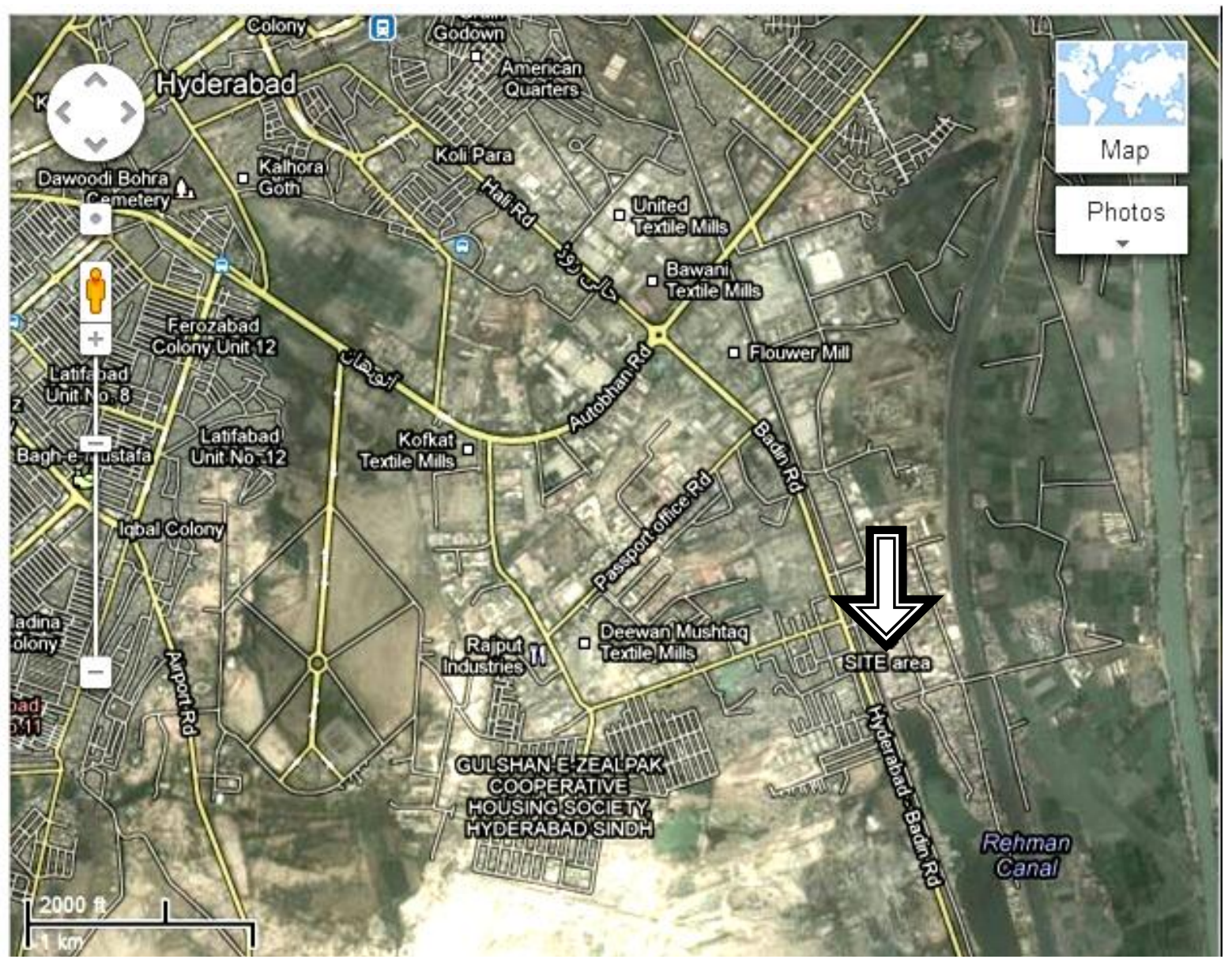

Fig.-6: Location of Ghee Industries of SITE area Hyderabad (Sindh)

\subsection{Optimum Dosage of Chitosan}

Normally insufficient or overdosing of Chitosan ends in poor performance of waste water treatment. Therefore, in the treatment of waste water of ghee industry the optimum dose was obtained at $\mathrm{pH} 4$, with $500 \mathrm{rpm}$ swirling for 5 minutes and $100 \mathrm{rpm}$ swirling for 20 minutes and 25 minutes of settling time. Chitosan dose ranged from $0.25 \%$ to $2.0 \%$. Also the waste water sample of ghee industry was adjusted from the initial alkaline $\mathrm{pH}$ to $\mathrm{pH} 4$. It has been reported that amino $\left(\mathrm{NH}_{2}\right)$ groups as functional groups are protonated up to $90 \%$ on chitosan surface at $\mathrm{pH} 4$ and reduced to $50 \%$ at $\mathrm{pH} 6$ [2]. The $\mathrm{pH}$ was controlled with addition of small quantities of strong acid $(\mathrm{HCl})$ or strong base $(\mathrm{NaOH})$. The effect of chitosan on waste water samples of ghee industry dictates the chitosan dosage for treatment of COD, Turbidity, TDS and Conductivity levels. The optimum dosage of chitosan studied for above with eight solutions ranged from $0.25 \%, 0.50 \%, 0.75 \%, 1.0 \%, 1.25 \%, 1.50 \%, 1.75 \%$ and $2.0 \%$ solutions. The solution from $0.25 \%$ to $1.0 \%$ reduction was observed in waste water samples of ghee industry as shown in Figure-7.

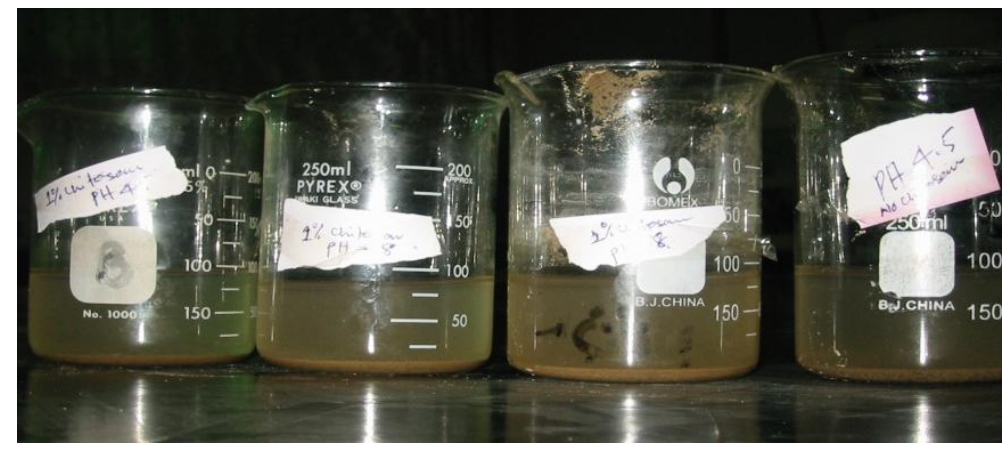

Fig.-7: Experimental work on Chitosan Dosage against variable $\mathrm{pH}$ values 
The solution which gave maximum response against all parameters was $1 \%$ chitosan solution at $\mathrm{pH} 4$. The waste water of ghee industries although claimed treated and discharged into canal as clean and safe for fields still contained lots of chemicals which need further industrial treatment. The important parameter COD $(\mathrm{mg} / \mathrm{L})$ found in waste water ghee samples of the area contained 1934 measured by COD VARIO Lovibond SN-09/14076 (Germany) with Reactor ET-108 Lovibond, against NEQS permissible limits for waste water $(<1000)$ was treated with chitosan under newly set optimum conditions and promising reduction in COD was achieved (383) that amounts $80.1 \%$ removal efficiency. Turbidity (NTU) of the sample found 69 measured with Turbidity Meter (HACH Model 2100 P, USA), crossed NEQS permissible limit $(<5)$ after subjecting to chitosan the value reduced to 5.6 with removal efficiency of $91.8 \%$. The two parameters TDS (mg/L) found 3108 and Conductivity $(\mu \mathrm{S} / \mathrm{cm})$ found 1987 entail absorption of chemicals in waste water were measured by Thermo Orion Conductivity Meter (Model 145, USA), therefore reduction in such parameters was achieved to a certain extent although the values were within range of NEQS permissible limits (TDS $<3500$ and Conductivity $<2500$ ). The secondary parameter Dissolved Oxygen (DO) was measured with YSI Pro20 Dissolved Oxygen Meter, USA, found $6.95 \mathrm{mg} / \mathrm{L}$ which is within range. The detailed description is shown in Table-2.

Table-2: Effect of Chitosan on Waste Water of Ghee Samples (SITE, Hyderabad)

\begin{tabular}{|c|l|c|c|c|c|}
\hline Sr.\#. & \multicolumn{1}{|c|}{ Parameters } & $\begin{array}{c}\text { Permissible } \\
\text { NEQS Limits }\end{array}$ & $\begin{array}{c}\text { Waste water } \\
\text { Ghee Industry }\end{array}$ & $\begin{array}{c}\text { Chitosan Treated } \\
\text { Waste Water }\end{array}$ & \% Reduction \\
\hline 1 & COD $(\mathrm{mg} / \mathrm{L})$ & $<1000$ & 1934 & 383 & 80.1 \\
\hline 2 & DO (mg/L) & 9.5 & 6.95 & --- & -- \\
\hline 3 & TDS (mg/L) & $<3500$ & 3108 & 852 & 72.5 \\
\hline 4 & Conductivity $(\mu S / \mathrm{cm})$ & $<2500$ & 1987 & 521 & 73.7 \\
\hline 5 & Turbidity (NTU) & $<5$ & 69 & 5.6 & 91.8 \\
\hline
\end{tabular}

The phenomenon of improvement in reduction of COD, Turbidity, TDS and Conductivity using chitosan was due to increased charge density of chitosan with respect to other polymeric materials [4].

\subsection{Optimum pH Value}

The $\mathrm{pH}$ value is very useful parameter which affects the surface charge of waste water solutions in terms of stability of suspensions. In present work the optimum $\mathrm{pH}$ was examined with chitosan dosage of $1.0 \%$ at 500 rpm swirling for 5 minute and $100 \mathrm{rpm}$ swirling for 20 minutes and 25 minutes of settling time from 2-10 pH. The optimum $\mathrm{pH}$ value where marked reductions in COD, Turbidity, TDS and Conductivity levels were observed falls in acidic medium at $\mathrm{pH} 4$ to $\mathrm{pH}$ 5. Because in acidic $\mathrm{pH}$ range the solubility of chitosan increases [2]. In present work the optimum $\mathrm{pH}$ value for treatment of waste water samples from ghee industry was observed at $\mathrm{pH} 4$ because the increased surface positive charge of amino groups of chitosan (cationic polyelectrolyte) reacted with anionic waste water ghee samples and making of rapid flocs was observed at that $\mathrm{pH}$ value which settled easily on mild shaking (coagulating process for anionic substances present in ghee samples via ionic or hydrogen bonding). The reduction with $1 \%$ chitosan of parameters COD up to $80.1 \%$, Turbidity up to $91.8 \%$, TDS up to $72.5 \%$ and Conductivity up to $73.7 \%$, in acidic $\mathrm{pH}$ was observed. It is a common understanding that solubility decreases as the $\mathrm{pH}$ of chitosan solution is increased towards the basic region because it becomes insoluble in alkaline $\mathrm{pH}$ [18], [32].

\subsection{Optimum Mixing Time}

The above parameters discussed provide sufficient information regarding flocs formation in case of required dosage while other one regarding growth in flocculation process i.e $\mathrm{pH}$. It is equally important to discuss the optimum mixing time regarding chitosan a polymeric flocculant, requires complete dispersion, adsorption and charge neutralization in a medium of colloidal solution. It is for this reason that study was conducted to ascertain the parameter regarding mixing time. During the studies it was observed that mixing rate and time affects the flocculation process. Longer mixing times yielded flocs breakage while shorter mixing times were insufficient to produce flocs in waste water ghee samples. During present work the optimum mixing time was examined with respect to [3], chitosan dosage of $1.0 \%$ at $500 \mathrm{rpm}$ swirling for 5 minute, $250 \mathrm{rpm}$ for 10 minutes and 100 $\mathrm{rpm}$ swirling for 20 minutes and 25 minutes time for settling at $\mathrm{pH} 4$. With these mixing times the waste water samples from ghee industry were treated and reduction in values of COD up to $80.1 \%$, Turbidity up to $91.8 \%$, TDS up to $72.5 \%$ and Conductivity up to $73.7 \%$ were achieved. The above strategy of mixing times with encouraging reduction in values suggests the optimum mixing time of 20 minutes. 


\section{CONCLUSION}

A new organic polymeric flocculant chitosan extracted locally from Indian prawns (Fenneropenaeus Indicus); was characterized by means of FTIR, TGA and further scanned with SEM and EDS for confirmation of presence of amino $\left(-\mathrm{NH}_{2}\right)$ and hydroxyl $(-\mathrm{OH})$ groups on skeletal chain. The extracted chitosan as flocculant was subjected to waste water samples of ghee industries located in SITE area of Hyderabad (Sindh). The promising removal and reductions for COD up to $80.1 \%$, Turbidity up to $91.8 \%$, TDS up to $72.5 \%$ and Conductivity up to $73.7 \%$ is a good sign that the same may become useful water purifier systems if the industrial effluents first compulsorily be treated with $1 \%$ chitosan solution at $\mathrm{pH} 4$, purified and then be discharged into canals and ravines.

\section{ACKNOWLEDGEMENT}

The authors are thankful to the Faculty of Chemical Engineering Department, MUET, Jamshoro, Sindh Pakistan, for providing research facilities at Analytical Chemistry Labs. The Flocculation process was performed in the laboratories of Chemical Engineering Department of MUET, Jamshoro, Sindh, Pakistan. The FTIR, NMR Spectroscopy, X-ray scattering, sorption techniques conducted commercially from the PCSIR Labs Karachi. The newly extracted chitosan material was examined by Scanning Electron Microscopy (SEM) technique in Scanning Electron Microscope Laboratory, Centre of Pure and Applied Geology University of Sindh Jamshoro. The frozen Indian prawns were obtained from the officials of Marine Fisheries Department Pakistan, West Wharf Karachi (Sindh), Pakistan. The authors are also thankful to Mr. Hussain Saleem, Assistant Professor \& Incharge Softronix Science Simulation Lab (FF-21, UBIT Building), Department of Computer Science, University of Karachi, Pakistan for providing support for performing data and graph analysis, and software based simulation, and document processing of this Research paper.

\section{REFERENCES}

[1] Chenite, C. Chaput, D. Wang, C. Combes, M.D. Buschmann, C.D. Hoemann, J.C Leroux, B.L. Atkinson, F. Binette, A. Selmani, (2000), "Novel Injectable Neutral Solutions of Chitosan form Biodegradable Gels in Situ", Biomaterials, 21 (21): 2155-2161.

[2] Domard, M. Rinaudo, and C. Terrassin, (1989), "Adsorption of Chitosan and a Quarternized Derivative on Kaolinite", Journal Applied Polymer Science. 38: 1799-1806.

[3] H. Mohd Ariffin, and L. L. Liew, (2007), "Wastewater Treatment at Petroleum Refinery by Using Chitosan in Flocculation", Universiti Teknologi Malaysia: Thesis Degree.

[4] L. Ahmad, S. Sumathi, and B. H. Hameed, (2006), "Coagulation of Residue Oil and Suspended Solid in Palm Oil Mill Effluent by Chitosan, Alum and PAC", Chemical Engineering Journal, 118, pp.99-105.

[5] Abdul Karim Shah, Zeenat M. Ali, Abdul Rehman Memon, A. Jabbar Laghari, Moina Akhtar Mughal, Syed Farman Ali Shah, Hussain Saleem, (2013), "Exploitation of Low Cost Coal Fly Ash Adsorbent with Coagulants for the Treatment of Industrial Complex Nature Dyes Wastewater", IJSER Vol. 4, Issue 9, pp.109-119.

[6] Abrar Saeed, Pedram Fatehi, Yonghao Ni, (2011), "Chitosan as a Flocculant for Pre-Hydrolysis Liquor of KraftBased Dissolving Pulp Production Process", Carbohydrate Polymers, Volume 86, Issue 4, pp.1630-1636.

[7] A. Bolto, (1995), Soluble Polymers in Water Purification”, Progress in Polymer Science, 20 (6): 987-1041.

[8] Riaño, B. Molinuevo, M. C. García-González, (2012), "Optimization of Chitosan Flocculation for MicroalgalBacterial Biomass Harvesting via Response Surface Methodology”, Ecological Engineering, Volume 38, Issue 1, pp.110-113.

[9] L. Chiang, C. T. Chang, H. Y. Sung, (2003), "Purification and Properties of Chitosanase from a Mutant of Bacillus Subtilis IMR-NK1", Enz. Microb. Technol. 32 (2): 260-267.

[10] F. Zeng, J. J. Wu, \& J. F. Kennedy, (2008), “Application of a Chitosan Flocculant to Water Treatment”, Carbohydrate Polymers, 71 (1): pp.135-139.

[11] D. Filion, M. Lavertu, and M. D. Buschmann, (2007), Ionization and Solubility of Chitosan Solutions Related to Thermo Sensitive Chitosan/Glycerol-Phosphate Systems", Biomacromolecules, 8(10): 3224-3234.

[12] D. Zeng, G. Yu, P. Zhang, Z. Feng, (2002), Production of Chitosan used for Flocculant in Medium Scale, Chinese Journal of Environmental Science, 1: 62-65.

[13] F. Franca, R. D. Lins, L. C. G. Freitas and T. P. Straatsma, (2008), "Characterization of Chitin and Chitosan Molecular Structure in Aqueous Solution”, J. Chem. Theory Comput. 4 (12): 2141-2149.

[14] E. L. Mogilevskaya, T. A. Akopova, A. N. Zelenetskii and A. N. Ozerin, (2006), The Crystal Structure of Chitin and Chitosan", Polymer Science Series A, 48(2): 116-123.

[15] Patel and R.T. Vashi, (2012), "Removal of Congo Red Dye from its Aqueous Solution using Natural Coagulants", Journal of Saudi Chemical Society, Volume 16, Issue 2, pp.131-136.

[16] Ionel Adrian Dinu, Marcela Mihai, Ecaterina Stela Dragan, (2010), "Comparative Study on the Formation and Flocculation Properties of Polyelectrolyte Complex Dispersions Based on Synthetic and Natural Polycations", Chemical Engineering Journal, Volume 160, Issue 1, pp.115-121. 
[17] J. Knapczyk, L. Krowczynski, B. Pawlik, Z. Liber, (1989), "In Chitin and Chitosan: Sources, Chemistry, Biochemistry, Physical Properties, and Applications”, Skjak-Braek, G., Anthonsen, T., Sandford, P., Eds.; Elsevier Applied Science: London, pp.665-669.

[18] J. Roussy, M. V. Vooren, B. A. Dempsey, and E. Guibal, (2005), "Influence of Chitosan Characteristics on the Coagulation and the Flocculation of Bentonite Suspensions", Water Research. 39. 3247-3258.

[19] Josefa M. Rangel, Beatriz Lopez, Maricruz Alvarez Mejia, Carlos Mendoza and Stephen Luby, (2003), “A Novel Technology to Improve Drinking Water Quality: A Microbiological Evaluation of In-Home Flocculation and Chlorination in Rural Guatemala", Journal of Water and Health, 01.1, pp.15-22.

[20] L. Chen, D. Chen, C. Wu, (2003), “A New Approach for the Flocculation Mechanism of Chitosan”, J. Polymer and the Environment, 11 (3): 87-92.

[21] M. A. A. Shadia, A. H. Hoda, E. M. Foukia, A. M. A. Nayera, (2008), "Partial Purification and Some Properties of the Chitosanases Produced by Bacillus Alvei NRC-14”, J. Appl. Sci. Research, 4: 1285-1290.

[22] M. Rinaudo, (2006), "Chitin and Chitosan: Properties and Applications", Prog. Polym. Sci., 31(7): 603-632.

[23] M. Yadav, A. Sand, K. Behari, (2012), "Synthesis and Properties of a Water Soluble Graft (Chitosan-G-2Acrylamidoglycolic Acid) Copolymer", International Journal of Biological Macromolecules, Volume 50, Issue 5, pp.1306-1314.

[24] Moina Akhtar Mughal, Akhtar H. Mughal, Zeenat M. Ali, Mohammad Yar Khuhawar, Hussain Saleem, (2013), "Antimicrobial Viscometric Studies of Thermally Stable Metal based Schiff Base Polymer derived from 4, 4Methylene Bis Furfuraldehyde", IJOART Vol. 2, Issue 8, pp.6-13.

[25] Moina Akhtar Mughal, Akhtar Mughal, Zeenat M. Ali, Ghulam Zuhra Memon, Mohammad Yar Khuhawar, Hussain Saleem, (2013), "New Antimicrobial Schiff base Polymers derived from 6, 6-Methylenebis (1-Napthaldehyde)", IJSER Vol. 4, Issue 9, pp.120-128.

[26] R. Bassi, S. O. Prasher, B. K. Simpson, (2000), "Removal of Selected Metal Ions from Aqueous Solutions using Chitosan Flakes", Sep. Sci. Technol. 35(4): 547-560.

[27] R. C. C. Domingues, S. B. F. Junior, R. B. Silva, V. L. Cardoso, M. H. M. Reis, (2012), "Clarification of Passion Fruit Juice with Chitosan: Effects of Coagulation Process Variables and Comparison with Centrifugation and Enzymatic Treatments," Process Biochemistry, Volume 47, Issue 3, pp.467-471.

[28] Rosana Rojas-Reyna, Simona Schwarz, Gert Heinrich, Gudrun Petzold, Sandra Schütze, Jörg Bohrisch, (2010), "Flocculation Efficiency of Modified Water Soluble Chitosan versus Commonly used Commercial Polyelectrolytes", Carbohydrate Polymers, Volume 81, Issue 2, pp.317-322.

[29] Rosângela Bergamasco, Leila Cristina Konradt-Moraes, Marcelo Fernandes Vieira, Márcia Regina Fagundes-Klen, Angélica Marquetotti Salcedo Vieira, (2011), "Performance of a Coagulation-Ultrafiltration Hybrid Process for Water Supply Treatment", Chemical Engineering Journal, Volume 166, Issue 2, pp.483-489.

[30] S. Hirano, H. Seino, Y. Akiyama, I. Nonaka, (1990), "Progress in Biomedical Polymers", Proceedings of an American Chemical Society Symposium; Gebelein, C. G., Dunn, R. L., Eds.; American Chemical Society: Washington, DC, pp 283-290.

[31] S. Schwarz, S. M. Ponce-Vargas, A. Licea-Claverie, C. Steinbach, (2012), "Chitosan and Mixtures with Aqueous Biocompatible Temperature Sensitive Polymer as Flocculants", Colloids and Surfaces A: Physicochemical and Engineering Aspects, In Press, Corrected Proof, Available online 28 March 2012.

[32] T. Takahashi, M. Imai, and I. Suzuki, (2005), "High-Potential Molecular Properties of Chitosan and Reaction Conditions for Removing p-quinone from the Aqueous Phase”, Biochemical Engineering Journal. 25. pp.7-13.

[33] T. Varawut, N. Pongchaisirikul, V. P. Hoven, (2003), "Surface Modification of Chitosan Films: Effects of Hydrophobicity on Protein Adsorption", Carbohydrate Research, 338 (9): 937-942.

[34] United Nations, (1996), "Human Development Report 1996, United Nations Development Program", Oxford University Press, New York.

[35] W.H.O. (1992), "The International Drinking Water Supply and Sanitation Decade: End of Decade Review", WHO/CWS/92.12, World Health Organization, Geneva.

[36] W.H.O. (1999), “The World Health Report 1999”. World Health Organization, Geneva.

[37] X. Liu, H. Seki, H. Maruyama, (2012), "Flocculation of Kaolin and Kanto Loam by Methylated Soy Protein", Separation and Purification Technology, Volume 93, pp.1-7.

[38] Xue Jiang, Ke Cai, Jing Zhang, Yan Shen, Shugen Wang, Xiuzhi Tian, (2011), "Synthesis of a Novel Water-Soluble Chitosan Derivative for Flocculated Decolorization", Journal of Hazardous Materials, Volume 185, Issues 2-3, pp.1482-1488.

[39] Zeenat M. Ali, Abdul Jabbar Laghari, Abdul Khalique Ansari, Mohammad Yar Khuhawar, (2013), "Synthesis and Characterization of Carboxymethyl Chitosan and its Effect on Turbidity Removal of River Water", IOSR Journal of Applied Chemistry (IOSR-JAC), Vol. 5, Issue 3, pp.72-79.

[40] Zeenat M. Ali, Moina Akhtar Mughal, A. Jabbar Laghari, A. K. Ansari, Hussain Saleem, (2013), "Polymeric Cellulose Derivative: Carboxymethyl-Cellulose as useful Organic Flocculant against Industrial Waste Waters", IJOART Vol. 2, Issue 8, pp.14-20.

[41] Zhen Yang, Yabo Shang, Yaobo Lu, Yichun Chen, Xin Huang, Aimin Chen, Yuxiang Jiang, Wei Gu, Xiaozhi Qian, Hu Yang, Rongshi Cheng, (2011), "Flocculation Properties of Biodegradable Amphoteric Chitosan-Based Flocculants", Chemical Engineering Journal, Volume 172, Issue 1, pp.287-295. 


\section{AUTHORS}

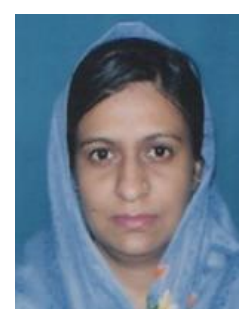

Zeenat Muhammed Ali is presently working as Assistant Professor in Chemical Engineering Department, Mehran University of Engineering \& Technology (MUET), Jamshoro, Sindh, Pakistan. She is Ph.D. Research Scholar. Her dissertation work is in final stages of submission. She has also obtained B.E. in Chemical Engineering in 1997 and M.E. in Environment Engineering in 2002 from MUET, Jamshoro. She has extensively worked in the area of Flocculation under Ph.D. studies and extracted natural flocculants from their indigenous sources and applied for water treatment for removal of turbidity, total dissolved solids and heavy metals. She has presented her work in various national and international conferences. Her work is published in various journals of repute.

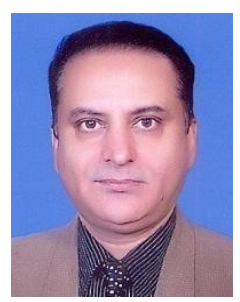

Abdul Jabbar Laghari is presently working as Director (Incharge) of Institute of Advanced Research Studies in Chemical Sciences (IARSCS) / HRL, University of Sindh, Jamshoro, Pakistan and Ex-Officio of Dr. M. A. Kazi Institute of Chemistry, University of Sindh, Jamshoro, Pakistan. He has teaching experience of 17 plus years. He is Ph.D. and worked extensively on the development of new mixed stationary phases for gas chromatography and gas chromatographic determination of metal ions. He is author of various research articles.

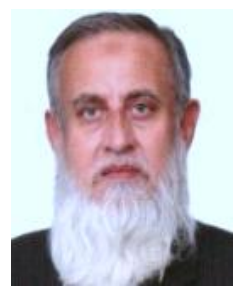

Abdul Khalique Ansari is Ph.D. and Professional Engineer having more than 35 years university teaching experience in the field of Chemical and Environmental Engineering. $\mathrm{He}$ is former Professor of Chemical and Environmental Engineering, Mehran Univrsity of Engg. \& Tech., Jamshoro, Sindh, Pakistan. Presently serving as Sr. Environmental Engineer, WSIPI at M. M. Pakistan (Pvt) Ltd. He has been engaged for more than 14 years in different capacities at Administrative \& Management positions during his service. He has also served for 10 years as subject and field specialist, developed PC-1 for the establishment of Institute of Environmental Engineering in Mehran University, Jamshoro. He has worked for SIDA (Sindh Irrigation \& Drainage Authority) to bring reform to achieve goals of equitable and reliable water supply to all farmers through participatory irrigation. He have produced more than 50 research publications with good impact factor in national \& International journals of repute.

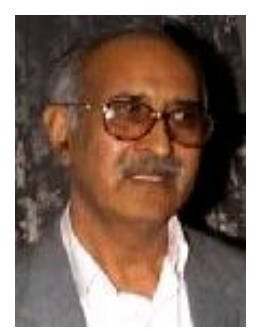

Muhammad Yar Khuhawar is Professor Emeritus, leading researcher and a versatile educator with distinguished academic carrier producing 25 Ph.D., 9 M.Phil. and 3 M.E. research scholars. He is honored with large number of National Awards, including Izaz-e-Kamal and Sitar-e-Imtiaz by President of Islamic Republic of Pakistan for achievements in scientific research. He is well known scholar having 35 years experience of teaching and research at higher education. Administrated number of fully funded research schemes and various academic tasks. National reputation for launching highly productive research workspace, in spite of meager research facilities available. He is actively committed to the field of research yielding over 283 publications in national and international journals. A large number of them are in the field of chromatography and electrophoresis for the analytical methods development for metals, non-metals and biological active compounds from wide variety of real samples; the synthesis of a number of schiff base polymers; new stationary phases for gas chromatography and sensitive liquid chromatography procedures for the determination of pesticide malathion. 